\title{
Cardiorespiratory Fitness, Smoking Status, and Risk of Incidence and Mortality From Cancer: Findings From the Veterans Exercise Testing Study
}

\author{
Baruch Vainshelboim, Zhongming Chen, Ricardo M. Lima, and Jonathan Myers
}

\begin{abstract}
Background: To assess the joint and stratified associations between cardiorespiratory fitness (CRF), incidence, and mortality from cancer in never, former, and current male smokers. Methods: CRF (treadmill exercise test) was assessed in 4694 men (never smokers [ $\mathrm{n}=1715]$; former smokers $[\mathrm{n}=1602], 32.4$ [30.5] pack-years; and current smokers [n $=1377], 40.3$ [26] pack-years) aged 58.1 (17.3) years, and prospectively followed for 12.7 (7.5) years. Multivariable Cox hazard models were analyzed. Results: In joint analyses, where high CRF in never smokers was used as a reference, hazard ratios and $95 \%$ (confidence intervals) for cancer incidence and cancer mortality were as follows: moderate CRF 1.41 (1.0-1.9) and 3.0 (1.7-5.5) in never smokers, 1.65 (1.3-2.2) and 3.7 (2.1-6.6) in former smokers, and $1.3(0.9-1.7)$ and $3.4(1.9-6.1)$ in current smokers, respectively. The corresponding values for low CRF were 1.53 (1.1-2.2) and 5.1 (2.7-9.5), 1.84 (1.3-2.5) and 6.6 (3.7-11.8), and 1.5 (1.12.2) and 5 (2.7-9.3), respectively. In stratified analyses by smoking status, compared with low CRF, moderate and high CRF were associated with a $32 \%$ to $78 \%$ reduction in cancer mortality risk $(P$ trend for all <.001). Conclusion: Higher CRF is associated with lower risk of incidence and mortality from cancer regardless of smoking status, supporting the potential preventive benefits for public health.
\end{abstract}

Keywords: public health, epidemiology, population attributable fraction, prevention strategy

Cancer is one of the leading causes of morbidity and mortality worldwide and in the United States. ${ }^{1-4}$ The American Cancer Society estimates that 1 in 3 men and women in the general population will develop some type of cancer during their lifetime, and 1 in 5 will die from cancer. ${ }^{4}$ Smoking is the single most important risk factor for cancer, accounting for approximately $25 \%$ of all cancer incidence and 30\% of total cancer mortality. ${ }^{1-3,5}$ The prevalence of current smokers is about $20 \%$ of the world's adult population (about 800 million men and 200 million women), ${ }^{1}$ ranging from approximately $17 \%$ of men in the United States to about $31 \%$ of men in the European Union. ${ }^{5,6}$ As most people are not currently smokers, including smokers and nonsmokers in a composite analysis of a general population could bias the risk for cancer. Despite the fact that smoking significantly increases the risk of cancer, ${ }^{1-5,7,8}$ most smokers do not develop cancer and, thus, there are factors other than smoking that influence risk. ${ }^{4,9-11}$

Low cardiorespiratory fitness (CRF) is an established risk factor for the development of many chronic conditions, and it is strongly associated with all-cause, cardiovascular and cancer mortality. ${ }^{12-14}$ Recently, the American Heart Association endorsed the adoption of CRF as a vital sign in clinical practice, making a strong case for including CRF in the risk paradigm. ${ }^{13}$ Although several reports have demonstrated an inverse association between CRF, cancer incidence, and cancer mortality in the general population, ${ }^{14-26}$ only a few studies have reported this association stratified by smoking

Vainshelboim is with the Master of Cancer Care Program, School of Health Sciences, Saint Francis University, Loretto, PA, USA. Vainshelboim, Chen, Lima, and Myers are with Cardiology Division, Veterans Affairs Palo Alto Health Care System/Stanford University, Palo Alto, CA, USA. Chen is with the School of Medicine, New York Medical College, Valhalla, NY, USA. Lima is with the Faculty of Physical Education, University of Brasília, Brasília, Brazil. Vainshelboim (baruch. v1981@gmail.com) is corresponding author. status. ${ }^{11,27}$ In this regard, one study has demonstrated that higher CRF was associated with lower cancer mortality in current smokers, ${ }^{11}$ whereas a more recent report found this association to be significant only among former smokers. ${ }^{27}$ This inconsistency with respect to the preventive role of CRF in cancer mortality as well as the association between CRF and cancer incidence across smoking status requires further exploration. Given that smokers and nonsmokers have potentially different risks for developing and dying from cancer, ${ }^{1-5}$ investigating the association between CRF, incidence, and mortality from cancer has important public health implications for prevention, screening, and treatment of smoking and nonsmoking individuals. Therefore, this study aimed to assess the association between CRF, total cancer incidence, and cancer mortality among never, former, and current male smokers. An additional aim was to quantify the potential public health impact of eliminating low CRF as a risk factor on cancer outcomes.

\section{Methods}

\section{Study Population}

The Veterans Exercise Testing Study has been previously described. ${ }^{28,29}$ In brief, the Veterans Exercise Testing Study cohort is an ongoing, prospective evaluation of primarily male Veterans (96\%) referred for exercise testing for clinical reasons, designed to address exercise test, clinical, and lifestyle factors and their association with health outcomes. The sample generally included participants with cardiometabolic risk factors, signs, or symptoms suggestive of cardiovascular disease, or known cardiometabolic disease. The study was approved by the institutional review board at Stanford University, CA, USA. All participants who underwent a treadmill exercise test at the Veterans Affairs Palo Alto Health Care System between 1987 and 2014 were considered for inclusion. 
Clinical information on diagnoses, risk factors, and health behaviors (smoking, alcohol, and drug abuse) was collected at the time of the exercise test using the Veterans Affairs Computerized Patient Record System and self-report health history. Of the 5540 participants who completed the baseline evaluation, 846 participants were excluded: women $(n=352)$, those with a history of any malignancy $(n=76)$, incomplete or prematurely terminated exercise tests $(n=192)$, and loss to follow-up $(n=226)$. A total of 4694 male veterans (never smokers $[n=1715]$, former smokers $[\mathrm{n}=1602]$, and current smokers [1377]) were included in the analysis and were followed for a mean of 12.7 (7.5) years. Never smokers were defined as those who never smoked or who have smoked less than 100 cigarettes in their lifetime and are currently not smoking. Former smokers were defined as those who smoked at least 100 cigarettes in their lifetime but who had quit smoking at the time of baseline testing, whereas current smokers were defined as those who had smoked at least 100 cigarettes in their lifetime and who are currently smoking. ${ }^{30}$

\section{Exposure Assessment (CRF)}

Participants underwent maximal symptom limited exercise tests using an individualized ramp treadmill protocol according to established guidelines. ${ }^{31,32}$ The exercise protocol included continuous, individualized increments in treadmill speed and grade adjusted to achieve a targeted duration between 8 and 12 minutes, as previously recommended. ${ }^{31,32}$ A 12-lead electrocardiogram, heart rate, blood pressure, and Borg 6 to 20 perceived exertion rating were continuously recorded throughout the tests, and standard criteria for test termination were used. ${ }^{31,32} \mathrm{CRF}$ in metabolic equivalents, METs, was calculated from peak treadmill speed and grade utilizing established metabolic equations from the American College of Sports Medicine. ${ }^{31}$ CRF was analyzed as a categorical variable divided into 3 categories (low CRF $<5$ METs, moderate CRF 5-10 METs, and high CRF $>10$ METs). ${ }^{13,17,33}$ Determination of low CRF ( $<5$ METs) as a risk factor was made according to recent recommendations from the American Heart Association. ${ }^{13}$

\section{Outcomes Ascertainment (Incidence and Mortality From Cancer)}

The Veterans Affairs Computerized Patient Record System was used for capturing cancer outcomes; total cancer incidence and cancer mortality were the primary outcomes. Previous reports have demonstrated that the Veterans Affairs death records are relatively complete compared with those from other sources, such as the Social Security Administration. ${ }^{34}$ The Veterans Affairs records also have good agreement (kappa $=.82-.91)$ with state death records ${ }^{35}$ and high sensitivity for incidence of several chronic conditions. ${ }^{36-38}$ Medical records were carefully reviewed by qualified medical personnel who were otherwise blinded to treadmill test results and other study information. Cancer diagnosis was verified using pathology reports and the International Classification of Diseases ninth and tenth edition codes. Cancer diagnosis and vital status for each patient were ascertained as of August 2015.

\section{Statistical Analysis}

Demographics and clinical data of the participants are presented as mean (SD) for continuous variables and absolute numbers or percentages for categorical variables. Analysis of variance was performed to compare the participants' ages across CRF categories and smoking status, as well as for all comparisons between never, former, and current smokers for the continuous variables. Chisquare tests were utilized for all comparisons of categorical data. Multivariable Cox proportional hazard models were used to assess the association between CRF, total cancer incidence, and cancer mortality. Both a stratified analysis by smoking status (never, former, and current smokers) and a joint analysis where high CRF in never smokers used as a reference were utilized. All risk models were adjusted for age, history of alcohol and drug abuse, dyslipidemia, hypertension, body mass index, smoking in pack-years, presence of cardiac and pulmonary disease, diabetes, and physical activity status (active or inactive). 2,39,40 Physical activity status was evaluated by a participant's response to the question: "Do you engage in some form of physical activity such as brisk walking, jogging, bicycling, or swimming, long enough to work up a sweat, get your heart thumping, or become short of breath at least 3 times per week?" Participants who answered yes were classified as active, whereas participants who answered no were classified as inactive. ${ }^{28,31,41,42}$ The hazard models also took into account competing events (death resulting from causes other than cancer). ${ }^{43,44}$ To address the potential reverse causality bias, a secondary analysis was performed after excluding participants who had less than 2 years follow-up. The proportional hazards assumption was evaluated graphically for CRF categories and was confirmed using the scaled Schoenfeld residuals.

Population attributable fraction (PAF\%) was determined for low CRF ( $<5$ METs) compared with moderate and high ( $\geq 5$ METs) CRF. ${ }^{13}$ PAF\% is a well-established metric quantifying the contribution of a risk factor to the burden of disease or death, and it represents the proportional reduction in population disease or mortality burden that would occur if exposure to the risk factor was eliminated (eg, no tobacco use). PAF\% was calculated according to the equation: $P(\mathrm{RR}-1) / 1+P(\mathrm{RR}-1) \times 100,{ }^{45}$ where $P=$ prevalence of the risk factor and $\mathrm{RR}=$ fully adjusted relative risk calculated from the Cox hazard model. ${ }^{46,47}$ Missing data were considered as missing completely at random and analyzed using complete case methods. ${ }^{48}$ Data report and presentation followed the Strengthening the Reporting of Observational Studies in Epidemiology guidelines. ${ }^{49}$ SPSS (version 23 ; IBM, Chicago, IL) was used for statistical analyses. The significance level was set at $P<.05$.

\section{Results}

The analytical sample included 4694 participants (1715 never, 1602 former, and 1377 current smokers) with a mean age of 58.1 (17.3) years. Demographic and clinical characteristics of the participants are presented in Table 1 . Approximately $53 \%$ had hypertension, $32 \%$ were obese, almost $30 \%$ had a history of cardiovascular disease, $6.5 \%$ had pulmonary disease, and $14.1 \%$ had diabetes at baseline. Former smokers compared with never and current smokers were older and had a higher prevalence of obesity, hypertension, dyslipidemia, and diabetes, and had a slightly lower CRF (Table 1). There was no significant difference in age between CRF categories for each smoking status classification: never smokers (low CRF, 55.3 y [16.3] y; moderate CRF, 55.3 y [17 y]; and high CRF, 57.2 y [17.3 y]; $P=.12$ ), former smokers (low CRF, 60.3 y [17.3 y]; moderate CRF, 62.2 y [18.4 y]; and high CRF, 61.9 y [17.8 y]; $P=.27$ ), and current smokers (low CRF, 57.5 y [16.8 y]; moderate CRF, 55.8 y [16.2 y]; and high CRF, 55.9 y [16.3 y]; $P=.37$ ).

During a mean follow-up of 12.7 (7.5) years, a total of 1203 cancers were diagnosed, 500 participants died from cancer, and 24 competing events occurred. Former smokers compared with never 
Table 1 Baseline Demographic and Clinical Characteristics of the Cohort

\begin{tabular}{|c|c|c|c|c|c|}
\hline & $\begin{array}{c}\text { Entire cohort } \\
(n=4694)\end{array}$ & $\begin{array}{c}\text { Never smokers } \\
(n=1715)\end{array}$ & $\begin{array}{c}\text { Former smokers } \\
(n=1602)\end{array}$ & $\begin{array}{l}\text { Current smokers } \\
(n=1377)\end{array}$ & $P$ value \\
\hline Age, y & $58.1(17.3)$ & $55.9(17)$ & $61.8(17.9)$ & $56.1(16.3)$ & $<.001$ \\
\hline Smoking, pack-years & $35.3(29)$ & 0 & $32.4(30.5)$ & $40.3(26)$ & $<.001$ \\
\hline Obesity, BMI $>30 \mathrm{~kg} / \mathrm{m}^{2}$ & $32 \%$ & $31 \%$ & $37.3 \%$ & $27 \%$ & $<.001$ \\
\hline History of drugs abuse & $1.6 \%$ & $0.4 \%$ & $1.9 \%$ & $3.9 \%$ & $<.001$ \\
\hline History of alcohol abuse & $2.4 \%$ & $0.9 \%$ & $3.4 \%$ & $3.4 \%$ & $<.001$ \\
\hline Hypertension & $52.9 \%$ & $54.1 \%$ & $57.2 \%$ & $46.3 \%$ & $<.001$ \\
\hline Dyslipidemia & $36.3 \%$ & $34.4 \%$ & $40.4 \%$ & $34.1 \%$ & $<.001$ \\
\hline Cardiovascular disease & $29.8 \%$ & $30.8 \%$ & $29.3 \%$ & $29 \%$ & .50 \\
\hline Pulmonary diseases & $6.5 \%$ & $2.7 \%$ & $9 \%$ & $8.4 \%$ & $<.001$ \\
\hline Diabetes & $14.1 \%$ & $12.5 \%$ & $19.4 \%$ & $9.5 \%$ & $<.001$ \\
\hline Antihypertensive drugs & $21.1 \%$ & $25.9 \%$ & $18.7 \%$ & $18.1 \%$ & $<.001$ \\
\hline Antihyperlipidemias drug & $8.8 \%$ & $7.9 \%$ & $12.8 \%$ & $5.2 \%$ & $<.001$ \\
\hline CRF, METs & $8.2(3.5)$ & $8.6(3.7)$ & $7.9(3.2)$ & $8.2(3.5)$ & $<.001$ \\
\hline Low CRF $<5$ METs & $16.8 \%$ & $15.4 \%$ & $18.5 \%$ & $16.6 \%$ & .02 \\
\hline Moderate CRF 5-10 METs & $55.8 \%$ & $54.8 \%$ & $56.1 \%$ & $56.8 \%$ & \\
\hline High CRF $>10$ METs & $27.4 \%$ & $29.9 \%$ & $25.4 \%$ & $26.6 \%$ & \\
\hline Physical inactivity & $47.2 \%$ & $45.3 \%$ & $47 \%$ & $50 \%$ & .14 \\
\hline Total cancer incidence, $\mathrm{n}(\%)$ & $1203(25.6)$ & $293(17.1)$ & $605(37.8)$ & $304(22.1)$ & $<.001$ \\
\hline Cancer mortality, n (\%) & $500(10.7)$ & $105(6.1)$ & $254(15.9)$ & $141(10.2)$ & $<.001$ \\
\hline Competing events, $\mathrm{n}(\%)$ & $24(0.5)$ & $5(0.3)$ & $13(0.8)$ & $6(0.4)$ & .04 \\
\hline
\end{tabular}

Abbreviations: BMI, body mass index; CRF, cardiorespiratory fitness; MET, metabolic equivalent. Note: Data are presented as mean (SD) or as a percentage of the group for categorical variables.

and current smokers had a higher incidence and mortality from cancer (Table 1). In stratified analyses by smoking status, CRF was associated with cancer incidence only in former smokers. Relative to low CRF, moderate and high CRF were associated with $7 \%$ and $29 \%$ reduced risks of cancer incidence. The corresponding hazard ratios (HR) and $95 \%$ confidence intervals (CIs) were 0.93 (0.75 to 1.2 ) and 0.71 ( 0.55 to 0.9$), P$ trend $=.03$. Both moderate and high CRF were significantly associated with reduced risk of cancer mortality in never, former, and current smokers (Table 2). In joint analyses in which high CRF in never smokers used as a reference, moderate and low CRF levels were associated with increased risk of incidence and mortality from cancer. There were no significant differences in risks of incidence and mortality from cancer between never, former, and current smokers who had high CRF (Figures 1 and 2). The risk of cancer incidence in current smokers was not different between low and moderate CRF (Figure 1). After exclusion of those with less than 2 years follow-up, CRF remained significantly associated with total cancer incidence and cancer mortality (both $P$ trend <.001). In stratified analyses by smoking status, CRF remained a significant predictor of cancer mortality only. Among never smokers $(\mathrm{HR}=0.57,95 \% \mathrm{CI}$ [0.37 to 0.92], and $0.24,[0.12$ to 0.48$], P$ trend $<.001$ ), former smokers ( $\mathrm{HR}=0.63,95 \% \mathrm{CI}$ [0.37 to 0.92], and 0.28, [0.17 to 0.45], $P$ trend $<.001)$, and current smokers $(\mathrm{HR}=0.78,95 \% \mathrm{CI}[0.51$ to $1.2]$, and $0.45,[0.26$ to 0.81$], P=.02$ ), for moderate and high $\mathrm{CRF}$, respectively, association between $\mathrm{CRF}$ and total cancer incidence was not significant in stratified analyses after exclusion of those with less than 2 years follow-up. PAFs $\%$ for cancer mortality were $8.1 \%, 95 \% \mathrm{CI}$ (4.4 to 10.4$) ; 8.7 \%, 95 \% \mathrm{CI}$ (6.2 to 11.1$)$; and $6.9 \%$, $95 \%$ CI (2.8 to 10) in never, former, and current smokers, respectively, but were not significant for cancer incidence (Table 3).

\section{Discussion}

The current study aimed to assess stratified and joint associations between CRF, total cancer incidence, and cancer mortality among never, former, and current male smokers. In addition, we sought to evaluate the potential public health implications of CRF in cancer prevention. The novel findings showed that in a joint analysis where never smokers with high CRF used as a reference, both moderate and low CRF were independently associated with elevated risk of total cancer incidence and cancer mortality among former and current smokers. In addition, regardless of smoking status, high CRF demonstrated comparable protective benefits against cancer incidence and cancer mortality (Figures 1 and 2). In stratified analyses, higher CRF was associated with lower risk of cancer incidence only in former smokers, whereas the risk of cancer mortality was significantly lower across all smoking strata (Table 2). After exclusion of those with less than 2 years follow-up, CRF remained a significant predictor of cancer incidence and cancer mortality in a joint analysis and a predictor of cancer mortality in stratified analyses. In addition, the PAF\% analysis revealed that by eliminating low $\mathrm{CRF}$ as a risk factor, $6.9 \%$ to $8.7 \%$ of cancer mortality could potentially be prevented in never, former, and current smokers (Table 3). Although these observations do not indicate causality, they have important public health implications for several reasons. First, smoking is the single most important risk factor for cancer, accounting for approximately $24 \%$ of all cancer incidence and $34 \%$ of all cancer mortality in men. ${ }^{2}$ Second, although current smokers are a considerable fraction of the entire adult population (approximately 20\%), ${ }^{1,3-5,8}$ most people do not smoke, and the assessed risk of cancer in the general population (combined smokers and nonsmokers) could potentially bias the risk 
Table 2 Multivariable Cox Hazard Models of CRF and Cancer Outcomes Stratified by Smoking Status

\begin{tabular}{|c|c|c|c|}
\hline & Never smokers & Former smokers & Current smokers \\
\hline Total cancer incidence & \multicolumn{3}{|c|}{ Hazard ratios $(95 \% \mathrm{CI})$} \\
\hline Low $\mathrm{CRF}<5$ METs & $\begin{array}{c}1 \\
\text { (reference) }\end{array}$ & $\begin{array}{c}1 \\
\text { (reference) }\end{array}$ & $\begin{array}{c}1 \\
\text { (reference) }\end{array}$ \\
\hline Events (n) & 50 & 114 & 64 \\
\hline Moderate CRF 5-10 METs & $0.92(0.66$ to 1.3$)$ & $0.93(0.75$ to 1.2$)$ & $0.86(0.63$ to 1.2$)$ \\
\hline Events (n) & 166 & 361 & 163 \\
\hline High CRF >10 METs & $\begin{array}{c}0.7 \\
(0.46 \text { to } 0.99)\end{array}$ & $\begin{array}{c}0.71 \\
(0.55 \text { to } 0.94)\end{array}$ & $\begin{array}{c}0.7 \\
(0.48 \text { to } 1)\end{array}$ \\
\hline Events (n) & 77 & 130 & 77 \\
\hline$P$ trend & .09 & .03 & .19 \\
\hline \multicolumn{4}{|l|}{ Cancer mortality } \\
\hline Low CRF $<5$ METs & $\begin{array}{c}1 \\
\text { (reference) }\end{array}$ & $\begin{array}{c}1 \\
\text { (reference) }\end{array}$ & $\begin{array}{c}1 \\
\text { (reference) }\end{array}$ \\
\hline Events (n) & 36 & 86 & 43 \\
\hline Moderate CRF 5-10 METs & $0.61(0.4$ to 0.9$)$ & $0.6(0.46$ to 0.79$)$ & $0.68(0.46$ to 0.99$)$ \\
\hline Events (n) & 57 & 143 & 75 \\
\hline High CRF >10 METs & $0.22(0.12$ to 0.42$)$ & $0.26(0.17$ to 0.4$)$ & $0.37(0.21$ to 0.62$)$ \\
\hline Events (n) & 12 & 25 & 23 \\
\hline$P$ trend & $<.001$ & $<.001$ & .001 \\
\hline
\end{tabular}

Abbreviations: CI, confidence interval; CRF, cardiorespiratory fitness; MET, metabolic equivalent. Note: The risk models were adjusted for age, history of drug and alcohol abuse, body mass index, dyslipidemia, hypertension, diabetes, presence of cardiac or pulmonary disease, pack-years in smoking, physical activity status, and accounting for competing events.

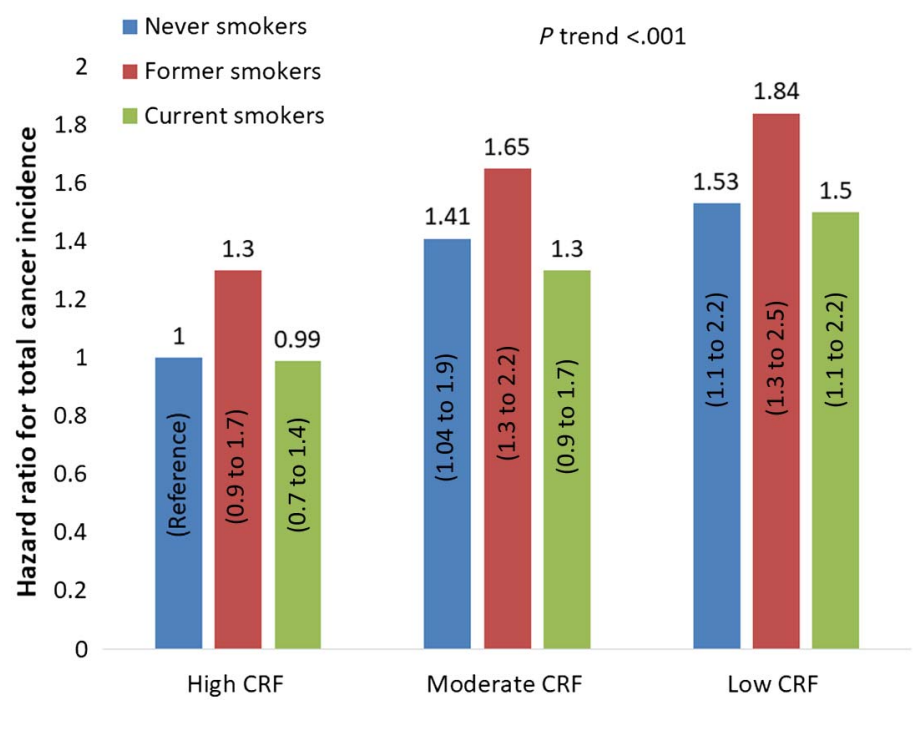

Figure 1 - Joint risk analysis between $\mathrm{CRF}$ and cancer incidence in never, former, and current male smokers. The risk model was adjusted for age, history of drug and alcohol abuse, body mass index, dyslipidemia, hypertension, diabetes, presence of cardiac or pulmonary disease, packyears in smoking, physical activity status, and accounting for competing events. CRF indicates cardiorespiratory fitness; MET, metabolic equivalent.

and requires a different approach. ${ }^{4,5}$ Third, cancer is one of the leading causes of morbidity and mortality, underscoring the importance of screening and prevention strategies. ${ }^{1,3-6,10}$ From a public health perspective, screening never, former, and current smokers for low CRF and achieving at least moderate CRF levels during

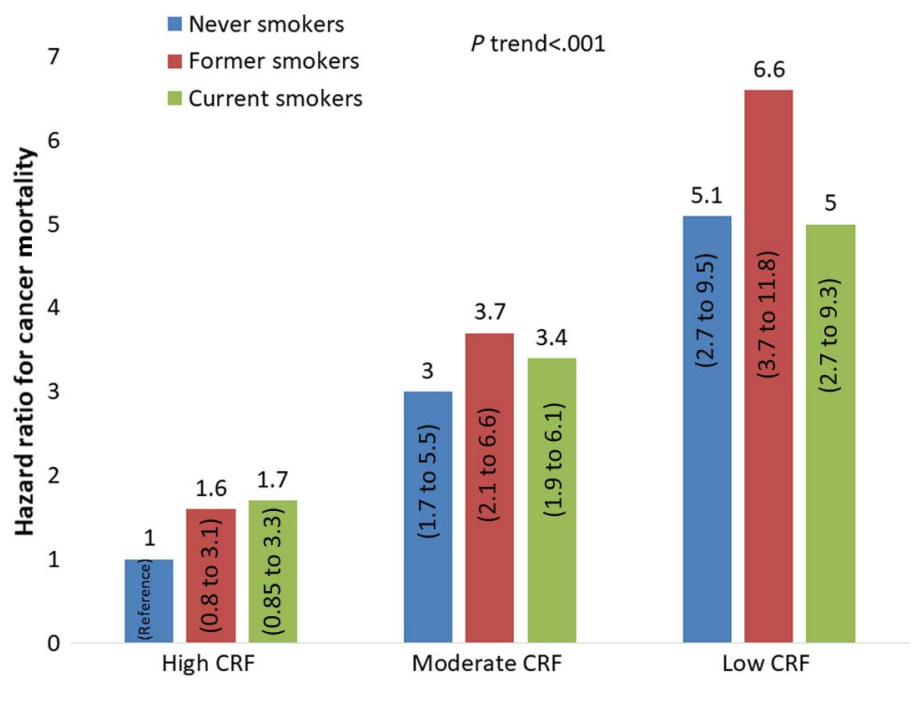

Figure 2 - Joint risk analysis between CRF and cancer mortality in never, former, and current male smokers. The risk model was adjusted for age, history of drug and alcohol abuse, body mass index, dyslipidemia, hypertension, diabetes, presence of cardiac or pulmonary disease, packyears in smoking, physical activity status, and accounting for competing events. CRF indicates cardiorespiratory fitness; MET, metabolic equivalent.

middle age could potentially reduce mortality from cancer and serve as important strategy for cancer prevention and control.

The current results are consistent with previous reports, generally showing a reduced risk of incidence and mortality from cancer with higher CRF among men. ${ }^{14-26}$ These findings also align with the few available reports on the association between CRF and 
Table 3 Relative Risk and Population Attributable Fraction of Low CRF for Cancer Incidence and Cancer Mortality in Never, Former, and Current Male Smokers

\begin{tabular}{|c|c|c|c|c|c|c|}
\hline & \multicolumn{3}{|c|}{ Cancer incidence } & \multicolumn{3}{|c|}{ Cancer mortality } \\
\hline & $\begin{array}{c}\text { Relative risks } \\
95 \% \mathrm{Cl}\end{array}$ & $\begin{array}{l}\text { PAFs } \% \\
95 \% \mathrm{Cl}\end{array}$ & $P$ value & $\begin{array}{c}\text { Relative risks } \\
95 \% \mathrm{Cl}\end{array}$ & $\begin{array}{l}\text { PAFs, \% } \\
95 \% \mathrm{Cl}\end{array}$ & $P$ value \\
\hline Never smokers & $1.2(0.9$ to 1.6$)$ & $2.6(-1.7$ to 5.8$)$ & .26 & $2.1(1.4$ to 3.1$)$ & $8.1(4.4$ to 10.4$)$ & $<.001$ \\
\hline Former smokers & 1.1 (0.9 to 1.4$)$ & $1.7(-2.1$ to 5.5$)$ & .22 & $1.9(1.5$ to 2.5$)$ & $8.7(6.2$ to 11.1$)$ & $<.001$ \\
\hline Current smokers & $1.2(0.9$ to 1.6$)$ & $2.8(-1.8$ to 6.2$)$ & .19 & 1.71 (1.2 to 2.5$)$ & $6.9(2.8$ to 10$)$ & .01 \\
\hline
\end{tabular}

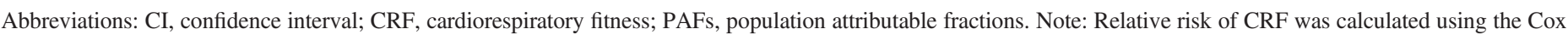

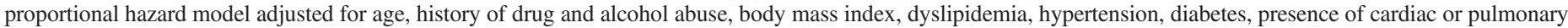
disease, pack-years in smoking, physical activity status, and accounting for competing events.

cancer mortality among smokers. ${ }^{11,27}$ The current study strengthens these earlier observations and adds several novel insights that have potentially important public health implications. To our knowledge, the results of the current study are the first to demonstrate the risk association between higher CRF and total cancer incidence in former smokers. Second, to our knowledge, these finding are the first to show that high CRF is associated with a comparable risk of incidence and mortality from cancer regardless of smoking status. Third, current smokers with either moderate or high CRF have a reduced risk of developing cancer. Finally, the PAF\% of low CRF for cancer mortality is also new and valuable information with respect to resource allocation and public health decisions for cancer prevention programs in never, former, and current smokers. Interestingly, in a stratified analysis, although, among former smokers, higher CRF was associated with lower risk of cancer incidence, among never and current smokers, this association was not significant (Table 2). This is likely due to the small number of cancer cases in each CRF category in never smokers, and may suggest that smoking cessation may have more of an impact than higher CRF for primary prevention of cancer incidence among current smokers. Future larger prospective studies are warranted to further explore these observations. Given that higher CRF is beneficial for reducing the risk of cancer outcomes regardless of smoking status, achieving at least moderate CRF could potentially reduce $6.9 \%$ to $8.7 \%$ of cancer mortality. ${ }^{1-6}$

Several physiological mechanisms have been proposed that may mediate the association between CRF and cancer. ${ }^{14,50-54}$ Potential protective pathways related to higher CRF might include reduced chronic-systemic inflammation (particularly C-reactive protein), which has been suggested as being carcinogenic in a broad spectrum of cancers., ${ }^{9,10,51}$ Improved immune function through an increased number of natural killer cells, an elevated antioxidant capacity, reduced oxidative stress and enhanced DNA repair, cell proliferation, and apoptosis are all potential mechanisms that could interact in a complex manner by blocking cancer cell initiation and countering cancer cell replication among fit individuals. ${ }^{10,14,50-56}$ However, despite growing observational evidence supporting the concept that CRF has a role in cancer prevention, ${ }^{9,11,15,17,18,21}$ prospective controlled studies addressing these mechanisms are warranted.

The strengths of the current study include its relatively large sample size $(\mathrm{n}=4694)$, extended follow-up period (mean of approximately $13 \mathrm{y}$ ), and prospective assessment of cancer outcomes. In addition, cancer outcomes were verified through the Veterans Affairs computerized medical records system, which has been demonstrated to be comparatively accurate and complete. ${ }^{34,37,38}$ CRF was quantified from treadmill exercise testing utilizing established protocols. ${ }^{31,32}$ This method has been widely used in epidemiologic studies and has been shown to strongly predict incidence and mortality from many chronic diseases, including cancer.9,11-13,17,18,26 Classification of CRF categories and determination of a low CRF threshold ( $<5$ METs) as a risk factor were set according to previous studies and recent recommendations from the American Heart Association, providing additional support for the association with cancer outcomes. ${ }^{13,17,33}$ The study also has several limitations. First, although our multivariable hazard models were adjusted for established covariates similar to those in previous studies, data on dietary habits were not collected, which may have an influence on cancer risk. ${ }^{9,11,17,18,21}$ Second, veteran participants are a unique population with a rich mixture of comorbidities that may have influenced the results by selection bias, although the findings are consistent with previous reports. ${ }^{9,11,15,17,18,21,27}$ Third, the study was limited to men, and the extent to which the findings apply to women needs to be examined in future studies. Fourth, due to a small number of cancer cases in each smoking strata, the analyses utilized a composite outcomes of total cancer incidence and cancer mortality. Fifth, exposure variables (smoking status and CRF) were assessed at baseline; the potential change during the follow-up is unknown. Finally, as is the case of all epidemiological studies, the findings provide an association between CRF and cancer outcomes, but preclude the establishment of cause and effect.

\section{Conclusion}

In a joint analysis, higher CRF was independently associated with a lower risk of total cancer incidence and cancer mortality among never, former, and current male smokers. High CRF shows a comparable risk of cancer outcomes, regardless of smoking status. In a stratified analysis, higher CRF was independently associated with a lower risk of cancer incidence only in former smokers, although a reduced risk of cancer mortality was significant across all smoking strata. Therefore, reducing the prevalence of low CRF among never, former, and current smokers could potentially lessen mortality from cancer and serve as a preventive strategy for public health. In addition to efforts directed toward smoking cessation, screening smokers and nonsmokers for low CRF and encouraging low-fit individuals to achieve at least moderate CRF through supervised exercise programs may play an important role in cancer prevention and control. Future prospective studies should address the role of promoting CRF for primary and secondary prevention of cancer among smokers and nonsmokers.

\section{Acknowledgments}

No funding was received. All authors declare there is no conflict of interest. 


\section{References}

1. World Health Organization. World Cancer Report 2014. Lyon: International Agency for Research on Cancer; 2014.

2. Islami F, Goding Sauer A, Miller KD, et al. Proportion and number of cancer cases and deaths attributable to potentially modifiable risk factors in the United States. CA Cancer J Clin. 2018;68(1):31-54. PubMed ID: 29160902 doi:10.3322/caac. 21440

3. Bray F, Ferlay J, Soerjomataram I, Siegel RL, Torre LA, Jemal A. Global cancer statistics 2018: GLOBOCAN estimates of incidence and mortality worldwide for 36 cancers in 185 countries. CA Cancer J Clin. 2018;68(6):394-424. doi:10.3322/caac.21492

4. American Cancer Society. Cancer Facts \& Figures 2019. Atlanta, GA: American Cancer Society; 2019.

5. American Cancer Society. Cancer Prevention \& Early Detection Facts \& Figures 2017-2018. Atlanta, GA: American Cancer Society; 2017.

6. Leon ME, Peruga A, McNeill A, et al. European code against cancer, 4th Edition: tobacco and cancer. Cancer Epidemiol. 2015;39(suppl 1):S20-S33. doi:10.1016/j.canep.2015.06.001

7. Whiteman DC, Wilson LF. The fractions of cancer attributable to modifiable factors: a global review. Cancer Epidemiol. 2016;44:203221. doi:10.1016/j.canep.2016.06.013

8. World Health Organization. WHO Report on the Global Tobacco Epidemic, 2017: Monitoring Tobacco Use and Prevention Policies. Geneva, Switzerland; 2017.

9. Sui X, Lee DC, Matthews CE, et al. Influence of cardiorespiratory fitness on lung cancer mortality. Med Sci Sports Exerc. 2010;42:872878. PubMed ID: 19996990 doi:10.1249/MSS.0b013e3181c47b65

10. Buffart LM, Singh AS, van Loon EC, Vermeulen HI, Brug J, Chinapaw MJ. Physical activity and the risk of developing lung cancer among smokers: a meta-analysis. J Sci Med Sport. 2014;17: 67-71. PubMed ID: 23528254 doi:10.1016/j.jsams.2013.02.015

11. Lee CD, Blair SN. Cardiorespiratory fitness and smoking-related and total cancer mortality in men. Med Sci Sports Exerc. 2002;34:735-739. PubMed ID: 11984287 doi:10.1097/00005768-200205000-00001

12. Bouchard C, Blair SN, Katzmarzyk PT. Less sitting, more physical activity, or higher fitness? Mayo Clin Proc. 2015;90:1533-1540. PubMed ID: 26422244 doi:10.1016/j.mayocp.2015.08.005

13. Ross R, Blair SN, Arena R, et al. Importance of assessing cardiorespiratory fitness in clinical practice: a case for fitness as a clinical vital sign: a scientific statement from the American Heart Association. Circulation. 2016;134:e653-e699. PubMed ID: 27881567 doi:10. 1161/CIR.0000000000000461

14. Schmid D, Leitzmann MF. Cardiorespiratory fitness as predictor of cancer mortality: a systematic review and meta-analysis. Ann Oncol. 2015;26:272-278. PubMed ID: 25009011 doi:10.1093/annonc/ mdu250

15. Laukkanen JA, Pukkala E, Rauramaa R, Makikallio TH, Toriola AT, Kurl S. Cardiorespiratory fitness, lifestyle factors and cancer risk and mortality in Finnish men. Eur J Cancer. 2010;46:355-363. PubMed ID: 19683431 doi:10.1016/j.ejca.2009.07.013

16. Robsahm TE, Falk RS, Heir T, et al. Measured cardiorespiratory fitness and self-reported physical activity: associations with cancer risk and death in a long-term prospective cohort study. Cancer Med. 2016;5(8): 2136-2144. PubMed ID: 27227704 doi:10.1002/cam4.773

17. Lakoski SG, Willis BL, Barlow CE, et al. Midlife cardiorespiratory fitness, incident cancer, and survival after cancer in men: the cooper center longitudinal study. JAMA Oncol. 2015;1:231-237. PubMed ID: 26181028 doi:10.1001/jamaoncol.2015.0226

18. Robsahm TE, Falk RS, Heir T, et al. Cardiorespiratory fitness and risk of site-specific cancers: a long-term prospective cohort study. Cancer Med. 2017;6(4):865-873. doi:10.1002/cam4.1043
19. Thompson AM, Church TS, Janssen I, Katzmarzyk PT, Earnest CP, Blair SN. Cardiorespiratory fitness as a predictor of cancer mortality among men with pre-diabetes and diabetes. Diabetes Care. 2008; 31:764-769. PubMed ID: 18162493 doi:10.2337/dc07-1648

20. Oliveria SA, Kohl HW, 3rd, Trichopoulos D, Blair SN. The association between cardiorespiratory fitness and prostate cancer. Med Sci Sports Exerc. 1996;28:97-104. PubMed ID: 8775361 doi:10.1097/ 00005768-199601000-00020

21. Pletnikoff PP, Tuomainen TP, Laukkanen JA, et al. Cardiorespiratory fitness and lung cancer risk: a prospective population-based cohort study. J Sci Med Sport. 2016;19:98-102. PubMed ID: 25800392 doi:10.1016/j.jsams.2015.02.008

22. Evenson KR, Stevens J, Cai J, Thomas R, Thomas O. The effect of cardiorespiratory fitness and obesity on cancer mortality in women and men. Med Sci Sports Exerc. 2003;35:270-277. PubMed ID: 12569216 doi:10.1249/01.MSS.0000053511.02356.72

23. Farrell SW, Cortese GM, LaMonte MJ, Blair SN. Cardiorespiratory fitness, different measures of adiposity, and cancer mortality in men. Obesity. 2007;15:3140-3149. doi:10.1038/oby.2007.374

24. Kampert JB, Blair SN, Barlow CE, Kohl HW, 3rd. Physical activity, physical fitness, and all-cause and cancer mortality: a prospective study of men and women. Ann Epidemiol. 1996;6:452-457. PubMed ID: 8915477 doi:10.1016/S1047-2797(96)00059-2

25. Sawada SS, Muto T, Tanaka H, et al. Cardiorespiratory fitness and cancer mortality in Japanese men: a prospective study. Med Sci Sports Exerc. 2003;35:1546-1550. PubMed ID: 12972875 doi:10.1249/01. MSS.0000084525.06473.8E

26. Pozuelo-Carrascosa DP, Alvarez-Bueno C, Cavero-Redondo I, Morais S, Lee IM, Martinez-Vizcaino V. Cardiorespiratory fitness and site-specific risk of cancer in men: a systematic review and metaanalysis. Eur J Cancer. 2019;113:58-68. PubMed ID: 30981949 doi:10.1016/j.ejca.2019.03.008

27. Sydo N, Merkely B, Carta KAG, et al. Effect of cardiorespiratory fitness on co-morbidities and mortality in never, past, and current smokers. Am J Cardiol. 2018;122:1765-1772. PubMed ID: 30266254 doi:10.1016/j.amjcard.2018.08.012

28. Myers J, Nead KT, Chang P, Abella J, Kokkinos P, Leeper NJ. Improved reclassification of mortality risk by assessment of physical activity in patients referred for exercise testing. Am J Med. 2015; 128:396-402. doi:10.1016/j.amjmed.2014.10.061

29. Myers J, Prakash M, Froelicher V, Do D, Partington S, Atwood JE. Exercise capacity and mortality among men referred for exercise testing. N Engl J Med. 2002;346:793-801. PubMed ID: 11893790 doi:10.1056/NEJMoa011858

30. Centers for Disease Control and Prevention. National Health Interview Survey; 2017.

31. American College of Sports Medicine. ACSM's Guidelines for Exercise Testing and Prescription. 9th ed. Philadelphia, PA: Wolters Kluwer/Lippincott Williams \& Wilkins Health; 2014.

32. Fletcher GF, Ades PA, Kligfield P, et al. Exercise standards for testing and training: a scientific statement from the American Heart Association. Circulation. 2013;128:873-934. doi:10.1161/CIR. 0b013e31829b5b44

33. Myers J, Kaykha A, George S, et al. Fitness versus physical activity patterns in predicting mortality in men. Am J Med. 2004;117:912918. doi:10.1016/j.amjmed.2004.06.047

34. Page WF, Mahan CM, Kang HK. Vital status ascertainment through the files of the Department of Veterans Affairs and the Social Security Administration. Ann Epidemiol. 1996;6:102-109. doi:10.1016/10472797(95)00126-3

35. Dominitz JA, Maynard C, Boyko EJ. Assessment of vital status in Department of Veterans Affairs national databases. Comparison with 
state death certificates. Ann Epidemiol. 2001;11:286-291. PubMed ID: 11399441 doi:10.1016/S1047-2797(01)00211-3

36. Kokkinos P, Faselis C, Myers J, et al. Exercise capacity and risk of chronic kidney disease in US veterans: a cohort study. Mayo Clin Proc. 2015;90:461-468. PubMed ID: 25792243 doi:10.1016/j. mayocp.2015.01.013

37. McCarron KK, Reinhard MJ, Bloeser KJ, Mahan CM, Kang HK. PTSD diagnoses among Iraq and Afghanistan veterans: comparison of administrative data to chart review. J Trauma Stress. 2014;27: 626-629. doi:10.1002/jts.21961

38. Floyd JS, Blondon M, Moore KP, Boyko EJ, Smith NL. Validation of methods for assessing cardiovascular disease using electronic health data in a cohort of veterans with diabetes. Pharmacoepidemiol Drug Saf. 2016;25:467-471. doi:10.1002/pds.3921

39. World Cancer Research Fund/American Institute for Cancer Research. Food, Nutrition, Physical Activity, and the Prevention of Cancer: A Global Perspective. Washington, DC: American Institute for Cancer Research; 2007.

40. Schuz J, Espina C, Villain P, et al. European code against cancer 4th edition: 12 ways to reduce your cancer risk. Cancer Epidemiol. 2015;39(suppl 1):S1-S10. doi:10.1016/j.canep.2015.05.009

41. Haskell WL, Lee IM, Pate RR, et al. Physical activity and public health: updated recommendation for adults from the American College of Sports Medicine and the American Heart Association. Circulation. 2007;116: 1081-1093. doi:10.1161/CIRCULATIONAHA.107.185649

42. Garber CE, Blissmer B, Deschenes MR, et al. American College of Sports Medicine position stand. Quantity and quality of exercise for developing and maintaining cardiorespiratory, musculoskeletal, and neuromotor fitness in apparently healthy adults: guidance for prescribing exercise. Med Sci Sports Exerc. 2011;43:1334-1359. PubMed ID: 21694556 doi:10.1249/MSS.0b013e318213fefb

43. Satagopan JM, Ben-Porat L, Berwick M, Robson M, Kutler D, Auerbach AD. A note on competing risks in survival data analysis. Br J Cancer. 2004;91:1229-1235. PubMed ID: 15305188 doi:10. 1038/sj.bjc.6602102

44. Fine JP, Gray RJ. A proportional hazards model for the subdistribution of a competing risk. J Am Stat Assoc. 1999;94:496-509. doi:10. 1080/01621459.1999.10474144

45. Northridge ME. Public health methods-attributable risk as a link between causality and public health action. Am J Public Health. 1995; 85:1202-1204. PubMed ID: 7661224 doi:10.2105/AJPH.85.9.1202
46. Song M, Giovannucci E. Preventable incidence and mortality of carcinoma associated with lifestyle factors among white adults in the United States. JAMA Oncol. 2016;2(9):1154-1161. PubMed ID: 27196525 doi:10.1001/jamaoncol.2016.0843

47. Greenland S. Interval estimation by simulation as an alternative to and extension of confidence intervals. Int J Epidemiol. 2004;33:13891397. PubMed ID: 15319402 doi:10.1093/ije/dyh276

48. Dziura JD, Post LA, Zhao Q, Fu Z, Peduzzi P. Strategies for dealing with missing data in clinical trials: from design to analysis. Yale J Biol Med. 2013;86:343-358.

49. Vandenbroucke JP, von Elm E, Altman DG, et al. Strengthening the Reporting of Observational Studies in Epidemiology (STROBE): explanation and elaboration. Ann Intern Med. 2007;147:W163-194. PubMed ID: 17938389 doi:10.7326/0003-4819-147-8-20071016000010-w1

50. Brown JC, Winters-Stone K, Lee A, Schmitz KH. Cancer, physical activity, and exercise. Compr Physiol. 2012;2:2775-2809. PubMed ID: 23720265

51. Hojman P, Gehl J, Christensen JF, Pedersen BK. Molecular mechanisms linking exercise to cancer prevention and treatment. Cell Metab. 2018;27:10-21. PubMed ID: 29056514 doi:10.1016/j.cmet.2017. 09.015

52. Westerlind KC. Physical activity and cancer prevention-mechanisms. Med Sci Sports Exerc. 2003;35:1834-1840. PubMed ID: 14600547 doi:10.1249/01.MSS.0000093619.37805.B7

53. Wiggins JM, Opoku-Acheampong AB, Baumfalk DR, Siemann DW, Behnke BJ. Exercise and the Tumor Microenvironment: potential Therapeutic Implications. Exerc Sport Sci Rev. 2018;46:56-64. PubMed ID: 29166299 doi:10.1249/JES.0000000000000137

54. Ashcraft KA, Peace RM, Betof AS, Dewhirst MW, Jones LW. Efficacy and mechanisms of aerobic exercise on cancer initiation, progression, and metastasis: a critical systematic review of in vivo preclinical data. Cancer Res. 2016;76:4032-4050. doi:10.1158/00085472.CAN-16-0887

55. Shephard RJ, Shek PN. Associations between physical activity and susceptibility to cancer: possible mechanisms. Sports Med. 1998;26: 293-315. PubMed ID: 9858394 doi:10.2165/00007256-19982605000002

56. Rundle A. Molecular epidemiology of physical activity and cancer. Cancer Epidemiol Biomarkers Prev. 2005;14:1899-1907. doi:10. 1158/1055-9965.EPI-04-0860 